INTERVENTIONAL CARDIOLOGY AND SURGERY

\title{
Cardiac ECMO for biventricular hearts after paediatric open heart surgery
}

\author{
R R Chaturvedi, D Macrae, K L Brown, M Schindler, E C Smith, K B Davis, G Cohen, V Tsang, \\ M Elliott, M de Leval, S Gallivan, A P Goldman
}

Heart 2004;90:545-551. doi: 10.1136/hrt.2002.003509

See end of article for authors' affiliations

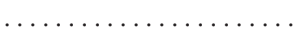

Correspondence to: Dr A Goldman,

Cardiothoracic Unit, Great

Ormond Street Hospital,

Great Ormond Street,

London WIN 3JH, UK.

goldmap@blueyonder.

co.uk

Accepted 20 March 2003

\begin{abstract}
Objective: To delineate predictors of hospital survival in a large series of children with biventricular physiology supported with extracorporeal membrane oxygenation (ECMO) after open heart surgery. Results: 81 children were placed on ECMO after open heart surgery. 58\% (47 of 81) were transferred directly from cardiopulmonary bypass to ECMO. Hospital survival was $49 \%$ (40 of 81 ) but there were seven late deaths among these survivors (18\%). Factors that improved the odds of survival were initiation of ECMO in theatre $(64 \%$ survival $(30$ of 47$))$ rather than the cardiac intensive care unit $(29 \%$ survival (10 of 34)) and initiation of ECMO for reactive pulmonary hypertension. Important adverse factors for hospital survival were serious mechanical ECMO circuit problems, renal support, residual lesions, and duration of ECMO.

Conclusions: Hospital survival of children with biventricular physiology who require cardiac ECMO is similar to that found in series that include univentricular hearts, suggesting that successful cardiac ECMO is critically dependent on the identification of hearts with reversible ventricular dysfunction. In our experience of postoperative cardiac ECMO, the higher survival of patients cannulated in the operating room than in the cardiac intensive care unit is due to early effective support preventing prolonged hypoperfusion and the avoidance of a catastrophic cardiac arrest.
\end{abstract}

$\mathrm{V}$ enoarterial extracorporeal membrane oxygenation (ECMO) is the most potent form of acute cardiorespiratory support available and enables complete relief of cardiac workload. Hence, it has been widely used for circulatory support after cardiac surgery with survival to hospital discharge being reported at $40-50 \% .^{1-12}$ It has also been used for a variety of cardiac medical conditions such as cardiomyopathy and myocarditis. ${ }^{13-15}$

However, there is only limited information on predictors of outcome and long term survival after hospital discharge in this ECMO population. There has also been only limited examination of the use of blood products and the impact of serious adverse circuit events. We reviewed our first 100 months of cardiac ECMO for hearts with biventricular physiology to determine outcomes and factors that contribute to survival.

\section{METHODS \\ Patients}

Retrospective review of our institution's ECMO database identified 81 patients who received venoarterial ECMO for cardiac support in a 100 month period (August 1992 to December 2000). During this period the same ECMO team also managed 203 neonatal and paediatric cases for noncardiac causes with a hospital survival of $72 \%$ and 15 patients who received cardiac ECMO for medical reasons (myocarditis or cardiomyopathy) or preoperative support (survival 27\%).

\section{ECMO management}

All patients had persistently poor perfusion and impaired ventricular function by echocardiography, despite optimised intravascular fluid status, inotrope or vasodilator treatment, and ventilator management. Patients who could not be weaned off bypass or who were unstable immediately afterwards underwent a 2-4 hour period of observation in theatre supported on bypass. ECMO was initiated if at least three attempts to wean the patient off bypass failed. Cannulation was performed directly through the aorta and right atrium with left atrial venting or through the internal jugular vein and carotid artery $(n=5)$. Incomplete decompression of the left ventricle can remain clinically silent for several hours. We believe this can have a very deleterious effect on ventricular recovery and hence all patients with either left ventricular or biventricular failure received a left atrial vent. Body weight determined whether a Stockert occlusive roller pump (Sorin Biomedica, Midhurst, West Sussex, UK) $(<10 \mathrm{~kg})$ or the Biomedicus pump (Medtronic, Watford, UK) (>10 kg) was used. Membrane oxygenators were the Medos 800 and 7000 (Medos, Stolberg, Germany) or the Avecor 0800 and 1500 (Sulzer Medica, Crawley, West Sussex, UK). The activated clotting time was maintained at 160-180 s. Bleeding during ECMO was managed by adjustment of heparin infusions and administration of blood products to maintain platelets $>150 \times 10^{9} /$, fibrinogen $>2.0 \mathrm{~g} / \mathrm{l}$, and prothrombin time $<14 \mathrm{~s}$ or activated partial thromboplastin time $<80 \mathrm{~s}$. Patients bleeding $>5 \mathrm{ml} / \mathrm{kg} / \mathrm{h}$ despite correction of blood factors received aprotinin and patients persistently bleeding $>10 \mathrm{ml} / \mathrm{kg} / \mathrm{h}$ underwent surgical re-exploration.

Readiness to be weaned from ECMO was evaluated by clinical assessment and echocardiography at a reduced pump flow every 48-72 hours. Before weaning, ventilator support, fluid status, and inotrope and vasodilator treatment were optimised. Pump flow was reduced over 1-4 hours and the circuit clamped off. Decannulation was performed following a satisfactory 1-2 hour period on conventional support.

Abbreviations: $\mathrm{ClCU}$, cardiac intensive care unit; $\mathrm{ECMO}$ extracorporeal membrane oxygenation; $\mathrm{ROC}$, receiver operating characteristic 


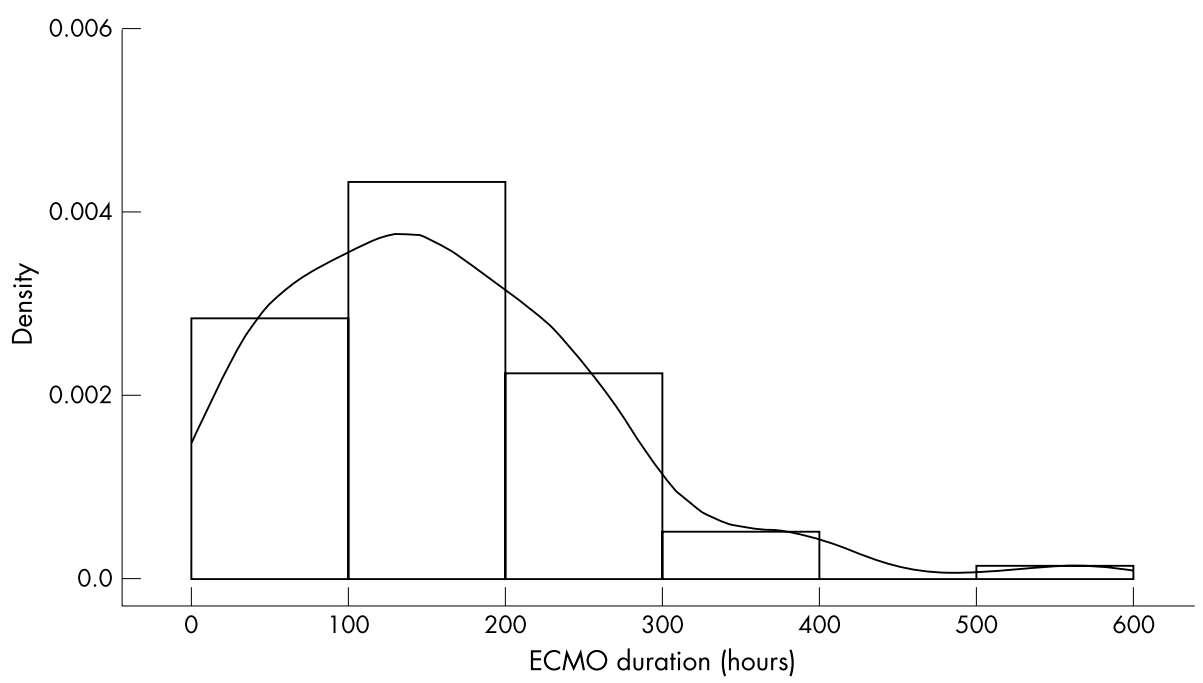

Figure 1 Distribution of extracorporeal membrane oxygenation (ECMO) run durations for the whole group plotted as a histogram and as a probability density curve (the area under both is 1). There is an extended tail to the right representing five patients with runs longer than 300 hours. Three of these patients had additional lung injury. Fourteen patients had ECMO runs longer than 240 hours.

\section{Data analysis}

The statistical package S-PLUS 6.1 (Insightful Corp, Basingstoke, UK) for Windows 2000 was used throughout. The data were explored with simple summary statistics and graphs (box plots, histograms, QQ plots, scatter plots). The distribution of duration of ECMO runs was described with a non-parametric probability density estimator (Gaussian kernel, automated selection of the bandwidth by the method of Sheather and Jones, MASS library version 6.2). ${ }^{16}$ This is an alternative to density estimation by histograms (fig l) that allows display of multiple distributions on the same graph (fig 2).The box plots used display a box that contains the interquartile range with a dot signifying the median, the whiskers (dashed line) cover 1.5 times the interquartile range, and outliers that lie outside this span are marked individually. Confidence intervals for the median are represented by the notches in the box (fig 3). A logistic regression model was developed by using the generalised linear model function and selecting explanatory variables by minimising the Akaike information criterion, using forward and backward stepping (MASS library version 6.2). ${ }^{16}$ It is tautological to use brain death as an explanatory variable for hospital survival and hence these patients were excluded from the logistic regression analysis. The small numbers in each diagnostic class made it impossible to use anatomical diagnosis as a variable; instead a simple six level classification of the complexity of operations based on a previously validated scale was used. ${ }^{17}{ }^{18} \mathrm{~A}$ model requiring six explanatory variables was selected from a saturated model. For the sake of clarity, variables such as duration of ECMO and aortic cross clamp time were allowed to remain in their usual continuous units, rather than being coerced into categorical variables such as aortic cross clamp time $>100$ minutes or aortic cross clamp time $\leqslant 100$ minutes. In the case of aortic cross clamp time this led to the odds ratio being close to unity and hence by odds ratio alone, not explicitly an adverse factor. Receiver operating characteristic (ROC) curves were plotted based on the logistic regression model derived. To construct these, the value of the logistic regression function was evaluated for each patient and used as a prognostic indicator of whether the patient would survive. A range of cut off values for this indicator was then used to construct a ROC curve to summarise the prognostic properties of the logistic regression function.

\section{RESULTS}

Eighty one patients were supported on ECMO after congenital heart surgery with a $49 \%$ survival to hospital

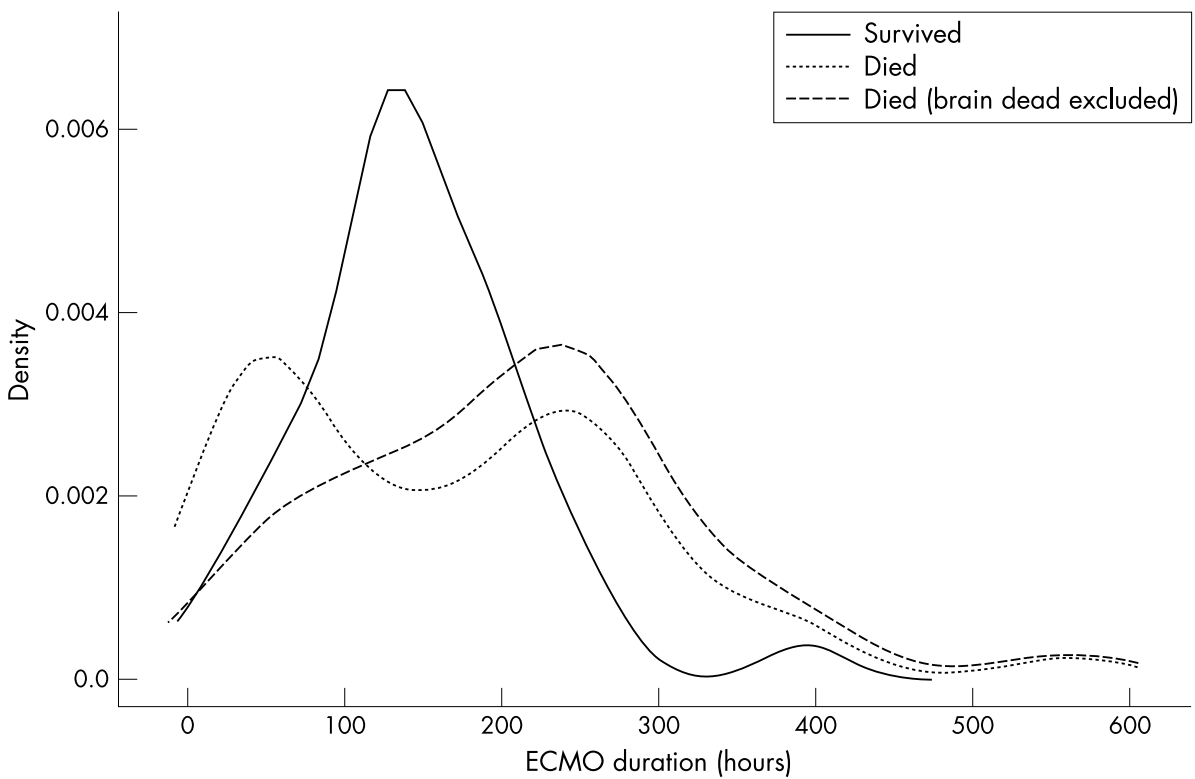

Figure 2 Distribution of ECMO run durations overlaps considerably for survivors and those who died. The density curve for survivors is close to a normal distribution, if the outlier is excluded (represented by the small peak at 393 hours). This patient had lung injury in addition to cardiac dysfunction. The first peak in the distribution of unsuccessful ECMO runs is due to withdrawal of support from patients with brain death. 


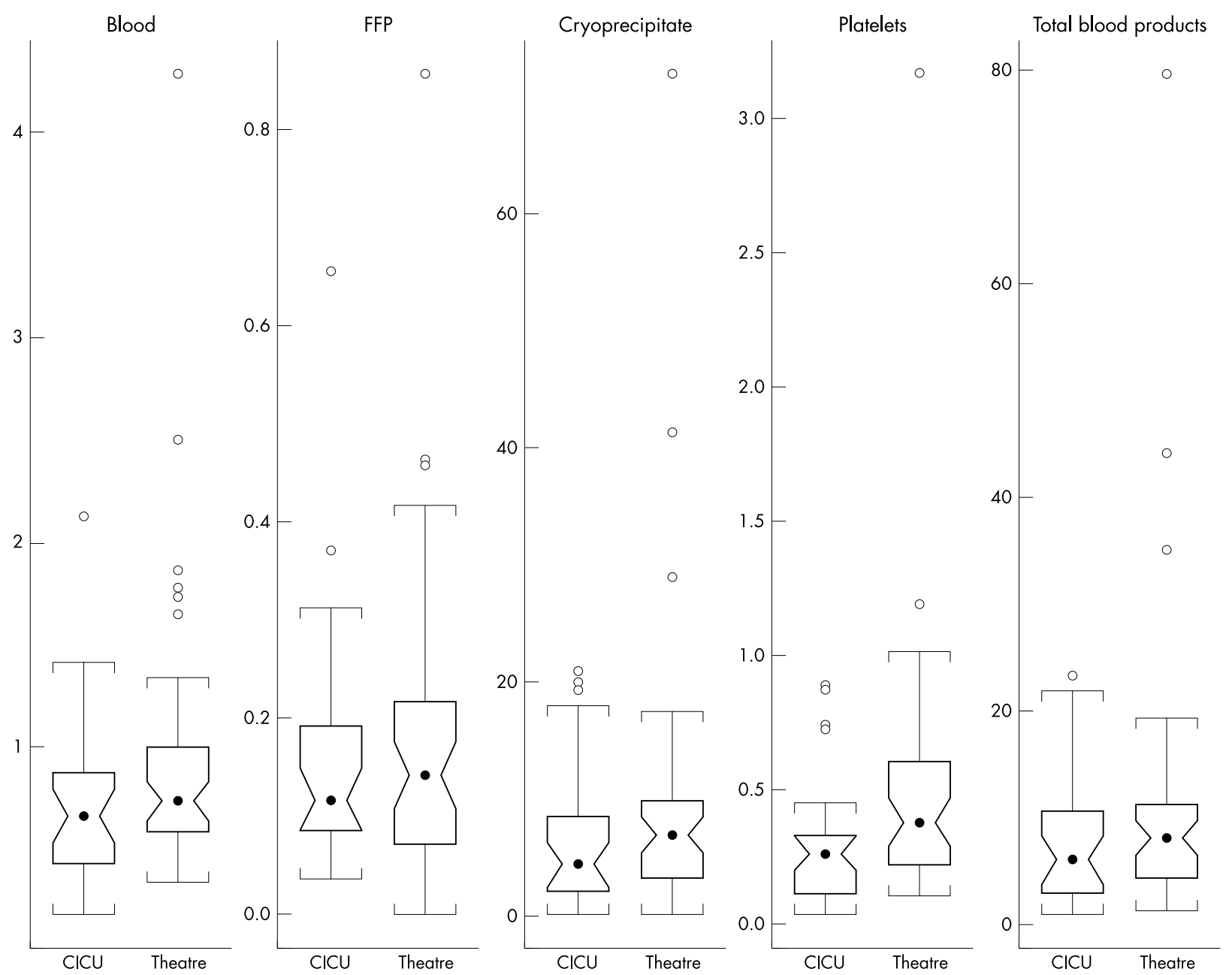

Figure 3 Large amounts of blood products were required, irrespective of the site of initiation of ECMO. An interval between cardiopulmonary bypass and ECMO resulted in a lower platelet transfusion rate in patients in the cardiac intensive care unit (CICU) $(p=0.0015)$. Box plot notches represent $95 \%$ confidence intervals. FFP, fresh frozen plasma.

Table 1 Summary of patients undergoing extracorporeal membrane oxygenation (ECMO) after open heart surgery

\begin{tabular}{|c|c|c|c|c|c|c|c|c|}
\hline Diagnosis & Number & Age (months)* & Weight $(\mathbf{k g})^{*}$ & CPR & $\begin{array}{l}\text { ECMO started } \\
\text { in } \mathrm{CICU}\end{array}$ & $\begin{array}{l}\text { ECMO duration } \\
\text { (hours)* }\end{array}$ & $\begin{array}{l}\text { ECMO } \\
\text { weaned } \dagger\end{array}$ & $\begin{array}{l}\text { Hospital } \\
\text { discharge }\end{array}$ \\
\hline Arterial switch & 23 & 0.6 & 3.4 & 14 & 6 & 121 & $16(67 \%)$ & $13(54 \%)$ \\
\hline Tetralogy of Fallot & $14 \ddagger$ & 8.8 & 7.3 & 8 & 11 & 232 & $3(21 \%)$ & $2(15 \%)$ \\
\hline LAWR & 9 & 27.6 & 9.0 & 1 & 0 & 141 & $7(78 \%)$ & $7(78 \%)$ \\
\hline TAPVC & 6 & 0.7 & 3.6 & 2 & 3 & 207 & $5(83 \%)$ & $4(67 \%)$ \\
\hline AS & $6 \S$ & 24.9 & 10.8 & 3 & 4 & 145 & $2(33 \%)$ & $2(33 \%)$ \\
\hline Transplant & 4 & 65.4 & 15.0 & 3 & 3 & 36 & $3(60 \%)$ & $2(40 \%)$ \\
\hline ALCA & 3 & 7.2 & 5.8 & 0 & 3 & 145 & 2 & 2 \\
\hline Truncus arteriosus & 3 & 0.6 & 2.7 & 1 & 1 & 133 & 2 & 2 \\
\hline VSD & 2 & $2.2-126$ & $4.2-23.0$ & 1 & 1 & $70-393$ & 2 & 1 \\
\hline AVSD & 2 & $3.3-9.6$ & $4.4-5.7$ & 1 & 1 & $187-294$ & 1 & 1 \\
\hline IAA & 2 & $0.1-1.6$ & $3.4-3.5$ & 1 & 1 & $70-137$ & 1 & 1 \\
\hline Endocarditis & 2 & $3.0-261.0$ & $2.7-70.0$ & 0 & 1 & $48-24$ & 0 & 0 \\
\hline Rastelli operation & 2 & $17.6-18.0$ & $6.9-10.6$ & 0 & 2 & $226-284$ & 1 & 1 \\
\hline Supravalvar AS & 1 & 55.6 & 16.8 & 0 & 0 & 33 & 0 & 0 \\
\hline LCA fistula & 1 & 6.4 & 6.0 & 0 & 0 & 194 & 1 & 1 \\
\hline Left isomerism & 1 & 0.4 & 3.1 & 0 & 0 & 166 & 1 & 1 \\
\hline Whole group & 81 & $2.4(0.6-13)$ & $4.5(3.3-8.7)$ & 35 & 37 & $144(70-226)$ & $47(58 \%)$ & $40(49 \%)$ \\
\hline
\end{tabular}

*Median; talive 24 hours after decannulation; łtetralogy of Fallot with absent pulmonary valve in one patient, tetralogy with complete atrioventricular septal defect in one; Sneonatal aortic stenosis in four, Ross procedure in two; Imedian (interquartile range).

ALCA, anomalous left coronary artery; AS, valvar aortic stenosis; AVSD, atrioventricular septal defect; CICU, cardiac intensive care unit; CPR, cardiopulmonary resuscitation; IAA, interrupted aortic arch; LAVVR, left atrioventricular valve replacement (one patient with congenitally corrected transposition); LCA, left coronary artery; TAPVC, total anomalous pulmonary venous drainage; VSD, ventricular septal defect. 
discharge $(n=40)$. Annual cardiac ECMO utilisation was $1-2.5 \%$ of all patients in the CICU. The median age was 2.4 months and the median weight was $4.5 \mathrm{~kg}$. Forty seven $(58 \%)$ of the postoperative ECMO runs were initiated in theatre, and this group had a significantly better hospital survival than those placed on ECMO in the CICU (30 (64\%) $v$ $10(29 \%), p=0.003)$. In the postoperative surgical group with ECMO initiated in the CICU the interval from cessation of cardiopulmonary support to starting ECMO was a median of 21.9 hours (interquartile range 15.4-47.7 hours).

\section{Duration of ECMO runs}

The median ECMO run duration was six days and the extended tail of the distribution of ECMO runs was mainly due to five patients with runs longer than 300 hours (fig 1). Three of these five patients were presumed to have lung injury superimposed on their initial cardiac failure, resulting in very prolonged ECMO runs in the hope of lung recovery (81st, 80th, and 77th longest runs). These patients had persistent bilateral whiteouts on chest radiographs and developed severe and rapid hypoxaemia rather than hypotension when ECMO flow was weaned. Lung injury is a difficult diagnosis in this context, as four patients had culture proven sepsis and two had severe pulmonary haemorrhage. Although these patients had good systolic function by echocardiography, none of them had end diastolic pressure measurements by cardiac catheterisation. Only one of the patients with the five longest runs survived to hospital discharge, and this patient had lung injury. This patient is the outlier represented by the small peak at 393 hours in the distribution of ECMO runs of survivors, which is otherwise close to a normal distribution (mean (SD) 139.5 (60.0) hours, 95\% confidence interval for mean 120.1 to 158.9 , 95\% confidence interval for SD 49.0 to 77.3 ) (fig 2). There are two prominent modes in the distribution of deaths (fig 2). The early peak is due to withdrawal of support from 10 patients in whom brain death became apparent early in the ECMO run. In the absence of neurological injury these patients' ECMO runs would have been extended pending cardiac recovery. Brain death was very strongly associated with cardiopulmonary resuscitation before initiation of ECMO (Fisher's exact test $\mathrm{p}=0.03$ ). Fifty six percent (19 of 34) of the patients put on ECMO in the CICU had had cardiopulmonary resuscitation in the 24 hours before initiation of ECMO.

\section{Outcome by diagnosis}

The most common diagnosis was the arterial switch operation ( $\mathrm{n}=23,54 \%$ survival) (table 1 ), although this indication has decreased dramatically in recent years. Nine of the arterial switch group were older than 21 days at the time of surgery. Four of these nine infants were discharged from hospital and the oldest survivor was 3.1 months old at the time of surgery. Ventricular septal defects were addressed in five patients at the time of the arterial switch: two with Taussig-Bing anomaly, two with large perimembranous defects, and one five month old who had received a pulmonary artery band for multiple ventricular septal defects. The only hospital survivor with transposition of the great arteries and ventricular septal defect was a patient with Taussig-Bing anomaly.

The group of patients supported on ECMO after tetralogy of Fallot repair had only a $15 \%$ survival $(n=2)$. Two of these patients were referred from another centre for ECMO. Haemodynamic collapse necessitating ECMO was frequently precipitated by an arrhythmia superimposed on poor right ventricular function (junctional ectopic tachycardia, $\mathrm{n}=7$; ventricular tachycardia, $\mathrm{n}=1$ ). Four patients had residual lesions requiring reoperation. One patient received a heart transplant but still required ECMO and later died of multiorgan failure. Three patients were examined after death and had histological evidence of myocardial infarction.

All nine patients who underwent left atrioventricular valve repair or replacement were placed on ECMO in theatre, with a $78 \%$ survival $(n=7)$ to hospital discharge. Five had left atrioventricular valve replacement, including one patient with congenitally corrected transposition.

Four patients were supported on ECMO after heart transplantation. Two had prolonged cardiac arrests during induction of anaesthesia, which resulted in brain death. The other two patients were successfully retransplanted from ECMO, the first after acute graft failure from ischaemia and the second with chronic rejection. Both were successfully discharged from hospital, although one died later.

Patients with aortic stenosis were either neonates who underwent open surgical valvotomy $(\mathrm{n}=3)$ or children after a Ross $(n=2)$ or Ross-Konno $(n=1)$ procedure. Two of the neonates with critical aortic stenosis died, one after support was withdrawn because of large bilateral intracranial haemorrhages. The patient who underwent the Ross-Konno procedure died after disintegration of her aorta around the arterial cannula. One of the patients who underwent the Ross procedure died of an obstructed right coronary artery despite receiving a right coronary artery graft five days after the Ross procedure. Ventricular function did not recover after this procedure.

All 13 patients with pulmonary hypertension received inhaled nitric oxide before ECMO and six patients were discharged from hospital. Pulmonary hypertension with right heart failure was the major mechanism necessitating ECMO in seven patients (arterial switch, $\mathrm{n}=3$; total anomalous pulmonary venous drainage, $\mathrm{n}=2$; truncus arteriosus, $\mathrm{n}=1$; mitral valve replacement, $\mathrm{n}=1$ ) and five of these survived to hospital discharge. The only patient with fixed increased pulmonary vascular resistance died.

\section{The impact of residual lesions}

Residual lesions were defined as haemodynamically significant and surgically remediable lesions present after the first procedure. Hence, myocardial infarctions were not classified as residual lesions. Twelve of the 81 patients (15\%; five of 12 survived) had residual lesions necessitating surgical correction: systemic atrioventricular valve regurgitation ( $\mathrm{n}=5$; one patient had two repairs), right ventricular outflow tract obstruction or pulmonary artery stenosis $(n=3)$, ventricular septal defect $(n=2$, one due to patch dehiscence, the other transferred from another hospital), and coronary artery abnormalities $(\mathrm{n}=2)$. A third of these residual lesions had not been diagnosed preoperatively $(\mathrm{n}=4)$. In the group as a whole, postmortem examination was done after $47 \%$ of the deaths and, although additional residual lesions were not found, myocardial infarction was confirmed in nine patients.

\section{Late deaths after hospital discharge}

Long term survival information was available for all patients. Seven of the 40 hospital survivors had died by the end of the study, a median of 93 days (interquartile range 49-21 1 days) after hospital discharge. Three of these late deaths were due to arterial switches, and two of these patients had had a very protracted post-ECMO course with multiple complications. The third patient who died of arterial switch died suddenly in her country of origin and at necropsy was found to have organising thrombus in her coronary arteries with 50-75\% occlusion. Two patients with small supra-annular left atrioventricular valve replacements (Carbomedics 16) died at home. One child who had ECMO after a complete atrioventricular septal defect and hypoplastic aortic arch 
Table 2 Important determinants of hospital survival for children placed on ECMO after open heart surgery

\begin{tabular}{ll}
\hline Variable & Odds ratio \\
\hline Adverse factors & \\
Serious circuit problem & 0.11 \\
Renal support & 0.37 \\
Residual lesions & 0.51 \\
ECMO duration & 0.81 \\
Blood product transfusion & 0.93 \\
Cross clamp time & 1.01 \\
Beneficial factors & 10.3 \\
Pulmonary hypertension & 2.29 \\
ECMO started in theatre & \\
\hline
\end{tabular}

augmentation returned 12 months later for relief of left atrioventricular valve stenosis but died during surgery. The last late death was a patient after his second heart transplant with rejection.

\section{Complications during ECMO}

\section{Mechanical and circuit problems}

Twenty two patients required circuit changes, usually related to oxygenator failure or air in the venous circuit. The most severe complications occurred in patients with air in the arterial circuit in whom emergency circuit changes had to be performed $(\mathrm{n}=5)$ or in whom poor tissue quality resulted in the tissue disintegrating around the cannulae $(n=2)$. Air embolism resulted in severe neurological injury and withdrawal of support from one patient. Both patients with tissue disintegration died.

\section{Renal support}

Twenty two patients received haemofiltration during ECMO and six of these patients survived. Only one patient required chronic dialysis after discharge.

\section{Bleeding}

A very large amount of blood products were consumed (fig 3), irrespective of whether patients were cannulated in the CICU or theatre (median, units $/ \mathrm{kg} /$ day): blood $0.7 v 0.7$, fresh frozen plasma $0.1 v 0.1$, cryoprecipitate $4.5 \vee 6.9$, platelets 0.3 $v 0.4$, and total blood products 6.1 $v$ 8.1. Only platelet transfusion was significantly higher for those cannulated in theatre than for those in the CICU (Wilcoxon rank sum test, $p=0.015)$. Sixty three per cent of the group $(n=51)$ underwent mediastinal exploration (median $=1$ ) to search for surgical causes of bleeding, many of them multiple times.

\section{Diaphragmatic paralysis}

Eight patients required diaphragmatic plication $(10 \%$ of the series). This may have been related to multiple thoracic explorations to investigate bleeding.

\section{Sepsis}

Twenty two patients had culture proven sepsis that developed during ECMO. The most common organisms were Staphylococcus aureus, Staphylococcus epidermidis, and a range of Gram negative rods (Pseudomonas and Klebsiella species) and Haemophilus species.

\section{Logistic regression analysis of hospital survival}

An exploratory logistic regression analysis was performed to determine variables important for hospital survival. Patients who developed brain death were excluded from the analysis, as decision making for them was not dependent on cardiac recovery and they had a very different ECMO course (fig 2). An effective model with eight explanatory variables was found, with an area under the ROC curve of 0.84. The most potent adverse factors were serious circuit problems, renal support, and residual lesions. Initiation of ECMO in theatre and for pulmonary hypertension were two important beneficial factors (table 2). Although aortic cross clamp time was required by the model to achieve a good fit, its odds ratio is difficult to classify, as it is close to unity (see Methods). On medical and biological grounds, aortic cross clamp time is a plausible adverse factor but with only a small effect.

\section{DISCUSSION}

The aim of cardiac ECMO is to profoundly unload the heart and decrease its work, allowing a finite time interval for the myocardium to recover from injury or an alternative means of support to be found (donor heart, implantable assist device). This period is rarely more than 14-21 days in most centres due to cumulative adversity. ${ }^{19}$

Our ECMO cohort is distinctive in that the patients had biventricular hearts and the majority of the patients had ECMO initiated in theatre. Hospital survival in our biventricular series is comparable with series from other centres that also include a substantial number of univentricular hearts. Our initial policy of offering cardiac ECMO only for biventricular hearts has been changed, as it has become clear that a patient's anatomical diagnosis and operative procedure are imprecise guides to the reversibility of ventricular dysfunction. $^{20}$

Fifty eight per cent of the group were transferred directly from cardiopulmonary bypass to ECMO, as they could not be separated from bypass despite multiple attempts over an extended period of observation (2-4 hours) in theatre. Surprisingly, these were the very patients with the best hospital survival in our series (30 of $47(64 \%)$ ). Reports from other centres have varied in whether they have found a beneficial $^{35}$ or a deleterious effect with ECMO initiation in theatre. $^{71011}$ Despite bleeding during ECMO being a major management problem and requiring a large amount of blood products, consumption of these products had only a modest impact on hospital survival compared with other variables in the model (odds ratio 0.93) (table 2). Importantly, apart from platelet transfusions, similar amounts of blood products were used in the groups of patients cannulated in CICU and in theatre. Other series have differed in whether severe bleeding affected survival. ${ }^{2711}$ The elective use of a circuit without an oxygenator has been proposed after the Norwood operation, with one benefit being the lower levels of anticoagulation that become feasible. ${ }^{21}$

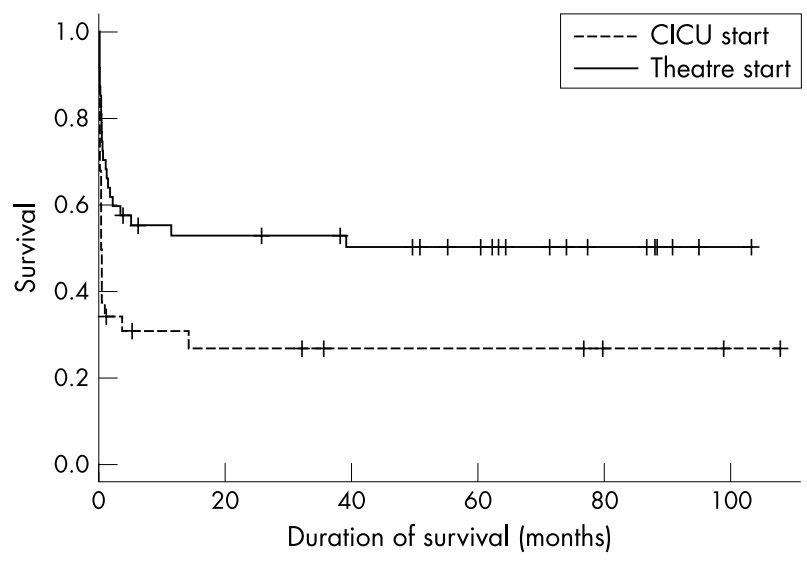

Figure 4 Survival curves for the postoperative cardiac ECMO patients vary with whether support was initiated early (theatre start) or later (CICU start). 
Serious ECMO circuit complications were often catastrophic events and their association with death is to be expected (two of 11 survived). Five of the episodes were related to air embolism in the arterial circuit and two were due to very friable tissue disintegrating around a cannula. Most of the serious circuit problems occurred early in the series and while the problems were not totally eradicated they have become much less frequent with increased team experience.

The ROC analysis of the performance of our logistic regression model illustrates that variables important in determining patient survival can be identified. However, it is important not to over interpret the results of this model, since it is a retrospective exploratory analysis and requires confirmation by a prospective study. There is a clear danger that the prognostic performance of the model has been overestimated. Even so, the results suggest that these techniques may have the potential for providing quantitative information about likely prognosis in a very difficult area of clinical decision making. This has analogies with work that has been carried out for adult patients in intensive care..$^{23}$

The late attrition after hospital discharge is of concern (fig 4) and, although the cause of death is unknown for some of these patients, it should be presumed to be cardiac in origin. The severe myocardial injury that necessitated ECMO almost certainly results in myocyte loss that may impair long term ventricular function. This remains a cause for vigilance and meticulous follow up of these patients is required after discharge.

Postoperative patients with low cardiac output are the largest users of cardiac ECMO in most centres. In the absence of a severe medical contraindication, virtually every postoperative patient is a candidate for this form of support. However, in most centres and for the Extra-Corporeal Life Support Organization (ELSO) database as a whole, the cardiac ECMO hospital survival rate is only $40-50 \%$. How can these results be improved? On the basis of our experience, the central tenets of successful cardiac ECMO are as follows.

\section{Selection of patients with reversible ventricular dysfunction}

Although the reversibility of ventricular dysfunction is often unknown at the time of cannulation, its critical importance to the success of cardiac ECMO is exemplified by three groups of patients:

- Postoperative patients with residual lesions. Such patients will not recover until these lesions are addressed surgically. ${ }^{6}$ Residual lesions impose an additional haemodynamic load on an already compromised myocardium, usually leading to deterioration. Despite prompt detection and reoperation, this was an important adverse factor in the logistic regression model.

- Postoperative patients with pulmonary hypertension. Postoperative reactive pulmonary hypertension with right heart failure is usually a transient phenomenon and with time the reactivity decreases and allows recovery of right heart function. In the logistic regression model pulmonary hypertension was a beneficial factor in determining outcome, presumably reflecting the temporal reversibility of the disease.

- Postoperative patients with extensive myocardial infarctions. These patients are not weaned from ECMO and should be considered for early listing for transplantation to maximise the chance of obtaining an organ. Nine patients in our group were found to have myocardial infarctions at the time of necropsy. Extensive myocardial necrosis may have contributed to the very disappointing results of ECMO for tetralogy of Fallot (table 1). Postoperative tetralogy of Fallot patients who develop low cardiac output with acute right ventricular restrictive physiology are known to have severe myocardial injury. ${ }^{24}$ Those in whom ventricular dysfunction is severe enough to necessitate mechanical support may have myocardial infarctions incompatible with ventricular recovery. Three of our patients with tetralogy of Fallot had evidence of myocardial infarction.

It is unlikely that much progress will be made in identifying reversible ventricular dysfunction by further refinement of current clinical criteria alone. New insight is required on the pathophysiology of intraoperative myocardial injury and the determinants of myocardial recovery.

\section{Avoidance of severe end organ damage before restoring adequate perfusion}

The general pattern of a decay and subsequent recovery of cardiac output after open heart surgery has been known for over 40 years, but there is considerable difficulty in anticipating the trajectory and absolute values of a given patient's cardiac output. ${ }^{25-27}$

The timing of initiation of ECMO in a controlled fashion before circulatory collapse is critically important in avoiding organ injury, particularly neurological damage. The results for the group cannulated in the CICU were adversely affected by the large number of patients who had cardiac arrests and received cardiopulmonary resuscitation before ECMO, which was significantly associated with brain death. Brain death became apparent during ECMO in 10 children. In six patients neurological injury was related to the need for resuscitation before ECMO and the time to adequate perfusion, as reflected in the significant association with prior cardiopulmonary resuscitation $(\mathrm{p}=0.03)$.

While there are clear guidelines for resuscitation efforts after a prolonged normothermic out-of-hospital arrest, ${ }^{28}$ the situation is more complex for in-hospital arrests in postoperative cardiac patients in whom early detection allows prompt and effective resuscitation with higher survival rates and in some centres in survivors even beyond 30 minutes of resuscitation. ${ }^{29}$ In the period covered by this study, limited resources prevented us from maintaining a perpetually primed circuit with appropriately trained resident staff. ${ }^{30}$ This contributed to delays in ECMO deployment for certain patients with precipitous deterioration.

A circuit is primed in anticipation of evolving instability for all borderline patients. Our team's cumulative cardiac and respiratory ECMO experience of more than 450 patients enables us to perform ECMO with low morbidity. Consequently we are now pursuing an aggressive strategy for early initiation of ECMO, with the aim of reducing the morbidity and mortality associated with prolonged periods of hypoperfusion and cardiac arrests. Clearly, a major challenge for the future is the identification of early predictors of severe cardiac dysfunction requiring ECMO.

In conclusion, our results show that early effective support with ECMO for potentially reversible myocardial dysfunction, before the occurrence of a prolonged cardiac arrest, was vital for a successful outcome in patients with severe cardiac failure after congenital heart surgery.

\section{ACKNOWLEDGEMENTS}

Rajiv Chaturvedi is supported by the British Heart Foundation.

\author{
Authors' affiliations \\ R R Chaturvedi*, Randall Centre, King's College, London, UK \\ D Macraet, K L Brown, M Schindler, E C Smith, G Cohen, V Tsang, \\ M Elliott, M de Leval, A P Goldman, Cardiothoracic Unit, Great Ormond \\ Street Hospital, London, UK
}


K B Davis, S Gallivan, Clinical Operations Research Unit, University College, London, UK

*Current address: Division of Cardiology, The Hospital for Sick Children, 555 University Avenue, Toronto, Ontario, Canada M5G 1X8 †Current address: Department of Paediatrics, Royal Brompton and Harefield NHS Trust, London SW3 6NP, UK

\section{REFERENCES}

1 Weinhaus L, Canter C, Noetzel M, et al. Extracoporeal membrane oxygenation for circulatory support after repair of congenital heart defects. Ann Thorac Surg 1989;48:206-12.

2 Meliones JN, Custer JR, Snedcor S, et al. Extracorporeal life support for cardiac assist in pediatric patients. Circulation 1991;84(suppl III):III168-72.

3 Delius RE, Bove EL, Meliones JN, et al. Use of extracorporeal life support in patients with congenital heart disease. Crit Care Med 1992;20:1216-22.

4 Raithel SC, Pennington GD, Boegner E, et al. Extracoporeal membrane oxygenation in children after cardiac surgery. Circulation 1992;86/suppl 2):11305-10.

5 Ziomek S, Harrell JE, Fasules JW, et al. Extracorporeal membrane oxygenation for cardiac failure after congenital heart operation. Ann Thorac Surg 1992;54:861-8

6 Black MD, Coles JG, Williams WG, et al. Determinants of success in pediatric cardiac patients undergoing extracorporeal membrane oxygenation. Ann Thorac Surg 1995:60:133-8.

7 Walters HL, Hakimi M, Rice MD, et al. Pediatric cardiac surgical ECMO: multivariate analysis of risk factors for hospital death. Ann Thorac Surg 1995;60:329-37

8 Kulik TJ, Moler FW, Palmisano JM, et al. Outcome-associated factors in pediatric patients treated with extracorporeal membrane oxygenator after cardiac surgery. Circulation 1996;94(suppl II):1163-8.

9 Del Nido PJ. Extracoporeal membrane oxygenation for cardiac support in children. Ann Thorac Surg 1996;61:336-9.

10 Langley SM, Sheppard SB, Tsang VT, et al. When is extracorporeal life support worthwhile following repair of congenital heart disease in children? Eur J Cardiothorac Surg 1998; 13:520-5

11 Duncan BW, Hraska V, Jonas RA, et al. Mechanical circulatory support in children with cardiac disease. J Thorac Cardiovasc Surg 1999:117:529-42.

12 Aharon AS, Drinkwater DC, Churchwell KB, et al. Extracoporeal membrane oxygenation in children after repair of congenital cardiac lesions. Ann Thorac Surg 2001;72:2095-102.

13 Del Nido PJ, Armitage JM, Fricker FJ, et al. Extracoporeal membrane oxygenation support as a bridge to pediatric heart transplantation. Circulation 1994;90:1166-9.
14 Duncan BW, Bohn DJ, Atz AM, et al. Mechanical circulatory support for the treatment of children with acute fulminant myocarditis. J Thorac Cardiovasc Surg 2001;122:440-8.

15 Kirshbom PM, Bridges ND, Myung RJ, et al. Use of extracorporeal membrane oxygenation in pediatric thoracic organ transplantation. J Thorac Cardiovasc Surg 2002;123:130-6.

16 Venables WN, Ripley BD. Modern applied statistics with Splus, 3rd edn. Heidelberg: Springer-Verlag, 1999.

17 Gallivan S, Davis KB, Stark JF. Early identification of divergent performance in congenital cardiac surgery. Eur J Cardiothorac Surg 2001;20:1214-9.

18 Jenkins KJ, Gauvreau K, Newburger JW, et al. Consensus-based method for risk adjustment for surgery for congenital heart disease. J Thorac Cardiovasc Surg 2002;123:110-8.

19 Anon. ECLS registry report. Ann Arbor: Extracorporeal Life Support Organization, 2001.

20 Pizarro C, Davis DA, Healy RM, et al. Is there a role for extracorporeal life support after stage I Norwood? Eur J Cardiothorac Surg 2001;19:294-301.

21 Darling EM, Kaemmer D, Lawson DS, et al. Use of ECMO without the oxygenator to provide ventricular support after Norwood stage 1. Ann Thorac Surg 2001;71:735-6.

22 Chang RW. Individual outcome prediction models for intensive care units. Lancet 1989;ii: 143-6.

23 Holmes L, Loughead K, Treasure T, et al. Which patients will not benefit from further intensive care after cardiac surgery? Lancet 1994;344:1200-2.

24 Chaturvedi RR, Shore DF, Lincoln C, et al. Acute right ventricular restrictive physiology after tetralogy of Fallot repair: association with myocardial injury and oxidative stress. Circulation 1999;100:1540-7.

25 Boyd AD, Tremblay RE, Spencer FC, et al. Estimation of cardiac output soon after intracardiac surgery with cardiopulmonary bypass. Ann Surg 1959; 150:613-26.

26 Burrows FA, Williams WG, Teoh KH, et al. Myocardial performance after repair of congenital cardiac defects in infants and children: response to volume loading. J Thorac Cardiovasc Surg 1988;96:548-56.

27 Wernovsky G, Wypii D, Jonas RA, et al. Postoperative course and hemodynamic profile after the arterial switch operation in neonates and infants: a comparison of low-flow cardiopulmonary bypass and circulatory arrest. Circulation 1995;92:2226-35.

28 Schindler MB, Bohn D, Cox PN, et al. Outcome of out-of-hospital cardiac or respiratory arrest in children. N Engl J Med 1996;335:1473-9.

29 Rhodes JF, Blaufox AD, Seiden HS, et al. Cardiac arrest in infants after congenital heart surgery. Circulation 1999;100(suppl II):II194-9.

30 Duncan BW, Ibrahim AE, Hraska V, et al. Use of rapid-deployment extracorporeal membrane oxygenation for the resuscitation of pediatric patients with heart disease after cardiac arrest. J Thorac Cardiovasc Surg $1998 ; 116: 305-11$

\section{ELECTRONIC PAGES}

\section{Heart Online case reports: www.heartinl.com}

7 he follow electronic only articles are published in conjunction with this issue of Heart.

\section{Acute myocardial infarction caused by paradoxical tumorous embolism as a manifestation of hepatocarcinoma \\ O Diaz Castro, H Bueno, L A Nebreda}

A 71 year old patient presented with a non-ST segment elevation acute myocardial infarction. The echocardiogram showed several masses attached to the interatrial septum. Several days after admission the patient died. A postmortem examination found a large hepatocarcinoma with intravascular and intracardiac metastases and several myocardial infarctions of different ages. The infarctions had been caused by coronary paradoxical embolisms through a patent foramen ovale and contained neoplastic cells from the liver carcinoma, which had not been diagnosed. The cause of death was a massive pulmonary embolism.

(Heart 2004;90:e29) www.heartjnl.com/cgi/content/full/90/ $5 / \mathrm{e} 29$
Successful treatment of left atrial disk thrombus on an Amplatzer atrial septal defect occluder with abciximab and heparin

F E Willcoxson, J D R Thomson, J L Gibbs

Acute device thrombosis is a rare but important complication after transcatheter atrial septal defect closure. In this case a mobile thrombus was noted on the left side of an Amplatzer atrial septal occluder after device release in a 12 year old boy with an uncomplicated atrial septal defect. The thrombus was successfully treated with an infusion of heparin and the glycoprotein IIa/IIIb receptor antagonist abciximab. Transoesophageal ultrasound performed the following day showed complete resolution of the clot. There are no reports to guide treatment of acute thrombosis in this setting. This combination of treatments was effective without complication in this case.

(Heart 2004;90:e30) www.heartjnl.com/cgi/content/full/90/ $5 / \mathrm{e} 30$ 